\title{
Students' Journal Paper Citing and Choice of Publisher: The Mediating Roles of Impact Factor and H-Index as Bibliometric Measures
}

\author{
Abdul Razak Ahmed, Xiaoyang Zhang*, Shi Yu \\ Research Institute of Scientific Information, Jiangsu University, Zhenjiang, China \\ Email: razakahmed08@gmail.com, *zhxy@ujs.edu.cn, 1047904566@qq.com
}

How to cite this paper: Ahmed, A.R., Zhang, X.Y. and Yu, S. (2019) Students' Journal Paper Citing and Choice of Publisher: The Mediating Roles of Impact Factor and H-Index as Bibliometric Measures. Open Access Library Journal, 6: e5696.

https://doi.org/10.4236/oalib.1105696

Received: August 11, 2019

Accepted: August 31, 2019

Published: September 3, 2019

Copyright $\odot 2019$ by author(s) and Open Access Library Inc.

This work is licensed under the Creative Commons Attribution International License (CC BY 4.0).

http://creativecommons.org/licenses/by/4.0/

\begin{abstract}
The purpose of this study was to investigate the relationship between journal citation preference (JCP) of scholars and their choice for publisher (CP) for their research papers. The study also considers the mediating roles played by journal impact factor (IF) and H-index (HI) on this relationship. Multiples linear regression analysis and the PROCESS Macro statistical tool were used to assess the main effects and mediating effects between the studied variables. From findings, CP had a $49.1 \%, 66.7 \%$ and $53.0 \%$ chance of its variations being explained by a unit increase in JCP, IF and HI respectively. In practical sense, the decision of a research student for a journal paper publisher is explained by the type of journal papers cited in the study up to about $50.0 \%, c e-$ teris paribus. Impact factor (IF) played a significant mediating role on the relationship between JCP and CP with an $\mathrm{r}^{2}$ of 0.588 against a 0.434 direct effect. Fir HI, an $r^{2}$ of 0.086 against a direct effect coefficient of 0.434 did not show significant mediation. It implies therefore that $\mathrm{CP}$ is influenced mostly by IF of journals.
\end{abstract}

\section{Subject Areas}

Library, Intelligence and Philology

\section{Keywords}

Journal Citation Preference, Impact Factor, H-Index, Research Publications

\section{Introduction}

Research is basically described with different words and statements that mean a process of asking questions about problems or subjects that are not well-understood and finding answers to such questions that may either solve the problems of so- 
ciety or add knowledge to advance an existing one. Looking at the relevance of research from such a definition, it is clear that educational institutions place so much importance on their ability to conduct meaningful and impacting researches that influence society positively [1] [2]. This need is more pronounced as the challenges and problems of society are increasing in numbers, aggravated by climate change and its adverse effects [3] [4] [5], socio-economic challenges with lack of peace in certain regions of the world [6], the challenges of hunger and nutrition [7] [8], health and sanitation, ageing and lifestyle changes among many other areas, not forgetting to mention technological advancement in many fields. The need for research, and for that matter, quality applicable research, cannot be overemphasized.

Universities and other research-oriented organizations place premium on the quality of their research publications, using bibliometric indices and measures of journal impact factor and H-index, [9] [10] [11]. The ranking of the research resourcefulness of such institutions and individual researchers in the world is also based on similar bibliometric assessments, [12]-[18]. For instance, [19] used the $\mathrm{H}$-index in assessing the productivity of social work scholars and found that H-index values were 3.97 for assistant professors; 8.59 for associate professors; and 16.14 for full professors. Thus, as a scholar ranked higher on the academic ladder, the H-index became higher, [19]. Owing to the level of importance attached to these indicators, research students from these universities are encouraged, and sometimes under the pressure of supervisors to undertake good quality research for publication in top ranked journals, specifically with emphasis on high impact factor journals [20] [21]. "Reference [2]" also argued that research ranking and reputation of researchers were significantly related. This has led to the practice of self-citation in which researchers improve their bibliometric indicators by citing themselves many times in their own studies [22] [23] [24]. "Reference [25]" found a strong relationship between the impact factor of journals and their citation rate. In this regard, manuscripts of research works are always scrutinized in blinded reviews of varying difficulty levels and decisions are taken by editors on the fate of such manuscripts. Fortunately for the research field and publishing houses in adhering to a "somewhat", "not-well-understood" standard, and unfortunately for the student or researcher whose manuscript gets rejected, this process is meant in most cases, to add to the relevance and the quality of submitted and published research works.

Several works have been done into understanding the relevance of using such bibliometric impact factor and H-index data to help in decision-making concerning the types of journals to consider for the publication of research works [26] [27] [28] [29]. Supervisors of research students incessantly coerce their students to target high impact factor journals and several higher learning institutions make this a prerequisite to successful scholarship and graduation. Ranking of journal based on bibliometric indicators therefore becomes the basis for choice of journal [30]. Research students therefore put in all the necessary efforts to meet the criteria of these high-class journals by making sure to cite relevant 
and current literature of high repute, ensure grammatical coherence of their write-ups, use highly acceptable and complex statistical techniques to elucidate hidden information in data, and as well meet ethical policies [18]. Research students are therefore left with no choice but to concur and make the necessary decisions regarding the choice of journals to consider for desired publications. However, there are several factors that may be suggestive in this decision-making process, of which the most prominent are impact factor and $\mathrm{H}$-index. This study aims to consider the relationship between students' journal citation preferences and actual choice of journal and the mediating roles that impact factor and $\mathrm{H}$-index may play as key bibliometric indices. The conceptual framework of this study is illustrated in (Figure 1).

\section{Study hypothesis}

1) $\mathrm{H}_{1}$ : Journal citation preference (JCP) has a significant effect on researcher's choice of publisher (CP) [2] [9].

2) $\mathrm{H}_{2}$ : Impact factor (IF) of journals plays a significant mediating role in the relationship between JCP and CP [26].

3) $\mathrm{H}_{3}: \mathrm{H}$-index $(\mathrm{HI})$ plays a significant mediating role in the relationship between JCP and CP [26].

\section{Methodology}

This study followed a quantitative research design, with a cross-sectional survey, using structured questionnaires. Randomly selected respondents were research students from the two Chinese Universities. One thousand, eight-hundred and twenty (1820) students were engaged through the administration of electronic survey questionnaires out of a total of two-thousand (2000), a ninety-one percent $(91.00 \%)$ response rate. Study variables (JCP, CP, IF and HI) were rated on a 10 -point ranking scale with 1 being the least important and 10 being the most important. Thus, the maximum mean score for each variable was 10 .

Data were organized into SPSS, coded and analyzed using basic descriptive statistics, and test statistics performed to verify data fitness using normality plots and tests for multicollinearity using the variance inflation factor (VIF) and correlation coefficients between variables. Multiple linear regression analysis was performed to establish the relationship between variables and the Process macro

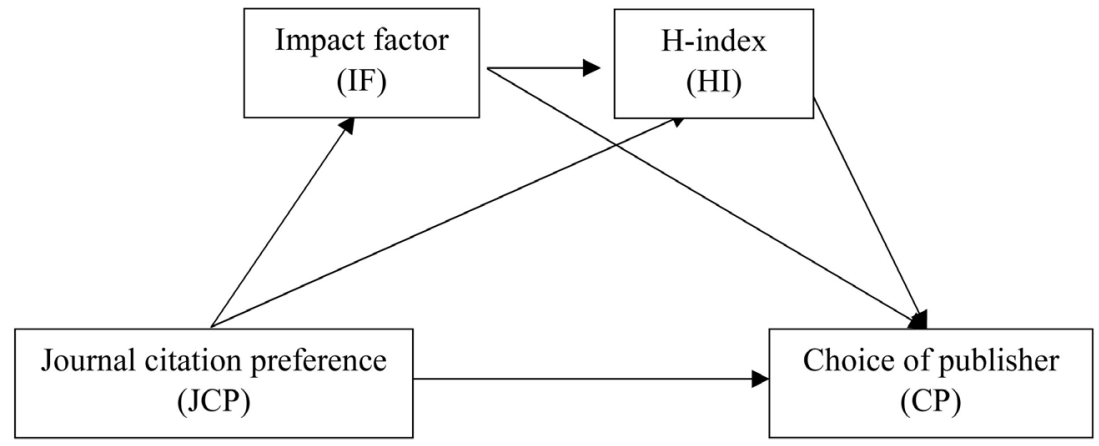

Figure 1. Framework, showing the relationship between study variables. 
utility of IBM-SPSS (Version 25) was used to test for mediation effects of IF and HI on the relationship between JCP and CP (Figure 1). The regression model used was generally represented as:

$$
\hat{Y}=\beta_{0}+\beta_{1} X_{1}+\beta_{2} X_{2}+\beta_{3} X_{3}+\varepsilon
$$

where $\beta_{0}$ is the constant and $\beta_{1,2,3}$ values are the coefficients of the variables $\left(X_{1,2,3}\right)$ and $\varepsilon$ being the error term. Substituting study variables into Equation (1), we have:

$$
\mathrm{CP}=\beta_{0}+\beta_{1} \mathrm{JCP}+\beta_{2} \mathrm{IF}+\beta_{3} \mathrm{HI}
$$

where CP was the dependent variable and JCP, IF and HI were the independent variables of the study.

\section{Results and Discussion}

\subsection{Fitness of Data}

Histogram and correlation analysis were used to test for normality of data distribution and multicollinearity between variables and results confirmed that data were suitable for the statistics to be performed and variables fit for multiple regression analysis. From (Table 1), there was no significant correlation between independent variables only but between independent variables and dependent variable (Figure 2 \& Figure 3 ). Thus, no multicollinearity existed in data.

\subsection{Multiple Regression Analysis}

The multiple linear regression models were significant $(\mathrm{P}<0.05)$ according to summary data and analysis of variance (ANOVA) (Table 2) and (Table 3). Model diagnostics showed $\mathrm{R}^{2}$ and adjusted $\mathrm{R}^{2}$ values of 0.711 and 0.699 respectively. This result showed that the independent variables (JCP, IF, HI) were able to account for up to $69.90 \%$ of the observation made in the dependent variable (CP).

Coefficients of the regression model (Table 4) were substituted into Equation (2) and the new model equation becomes:

$$
\mathrm{CP}=6.917 \pm 2.001+0.491 \pm 0.038 \mathrm{JCP}+0.667 \pm 0.104 \mathrm{IF}+0.530 \pm 0.092 \mathrm{HI} .
$$

From Equation (3), CP had a 49.1\%, 66.7\% and 53.0\% chance of its variations being explained by a unit increase in JCP, IF and HI respectively. Thus, the choice of a publisher as decided by a student is explained by each independent

Table 1. Correlations matrix between variables.

\begin{tabular}{cccccc}
\hline & & JCP & IF & HI & CP \\
\hline JCP & Pearson Correlation & 1 & 0.238 & 0.192 & $0.491^{\star *}$ \\
IF & Pearson Correlation & 0.238 & 1 & 0.267 & $0.667^{\star *}$ \\
HI & Pearson Correlation & 0.192 & 0.267 & 1 & $0.530^{\star *}$ \\
CP & Pearson Correlation & $0.491^{\star *}$ & $0.667^{\star *}$ & $0.530^{* *}$ & 1 \\
\hline
\end{tabular}

${ }^{* *}$ Correlation is significant at the 0.05 level (2-tailed). 
Table 2. Model summary

\begin{tabular}{ccccc}
\hline Model & $\mathrm{R}$ & R Square & Adj. R Square & Std. Error of the Estimate \\
\hline 1 & $0.823^{\mathrm{a}}$ & $\mathbf{0 . 7 1 1}$ & $\mathbf{0 . 6 9 9}$ & 2.3372
\end{tabular}

apredictors: (Constant), JCP, HI, IF; ' ${ }^{\mathrm{a}}$ Dependent Variable: CP.

Table 3. Analysis of variance (ANOVA) .

\begin{tabular}{ccccccc}
\hline \multicolumn{2}{c}{ Model } & Sum of Squares & df & Mean Square & F & Sig. \\
\hline & Regression & 7158.336 & 3 & 49.093 & 31.247 & $\mathbf{0 . 0 0 8}^{\mathrm{b}}$ \\
1 & Residual & 480.521 & 1816 & 3.411 & & \\
Total & 7638.857 & 1819 & &
\end{tabular}

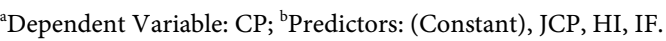

Table 4. Model coefficients.

\begin{tabular}{|c|c|c|c|c|c|c|}
\hline \multirow{2}{*}{\multicolumn{2}{|c|}{ Model variables }} & \multicolumn{2}{|c|}{ Unstandardized Coefficients } & \multirow{2}{*}{$\frac{\text { Standardized Coefficients }}{\text { Beta }}$} & \multirow{2}{*}{$\mathrm{t}$} & \multirow{2}{*}{ Sig. } \\
\hline & & $\mathrm{B}$ & Std. Error & & & \\
\hline \multirow{4}{*}{1} & (Constant) & 6.917 & 1.901 & & 2.063 & 0.010 \\
\hline & JCP & 0.491 & 0.038 & 0.491 & 1.911 & 0.001 \\
\hline & IF & 0.665 & 0.104 & 0.667 & 2.220 & 0.014 \\
\hline & $\mathrm{HI}$ & 0.530 & 0.092 & 0.530 & 3.305 & 0.032 \\
\hline
\end{tabular}

${ }^{\mathrm{a} D e p e n d e n t ~ V a r i a b l e: ~ C P . ~}$

Normal P-P Plot of Regression Standardized Residual Dependent Variable: $\mathbf{P}$

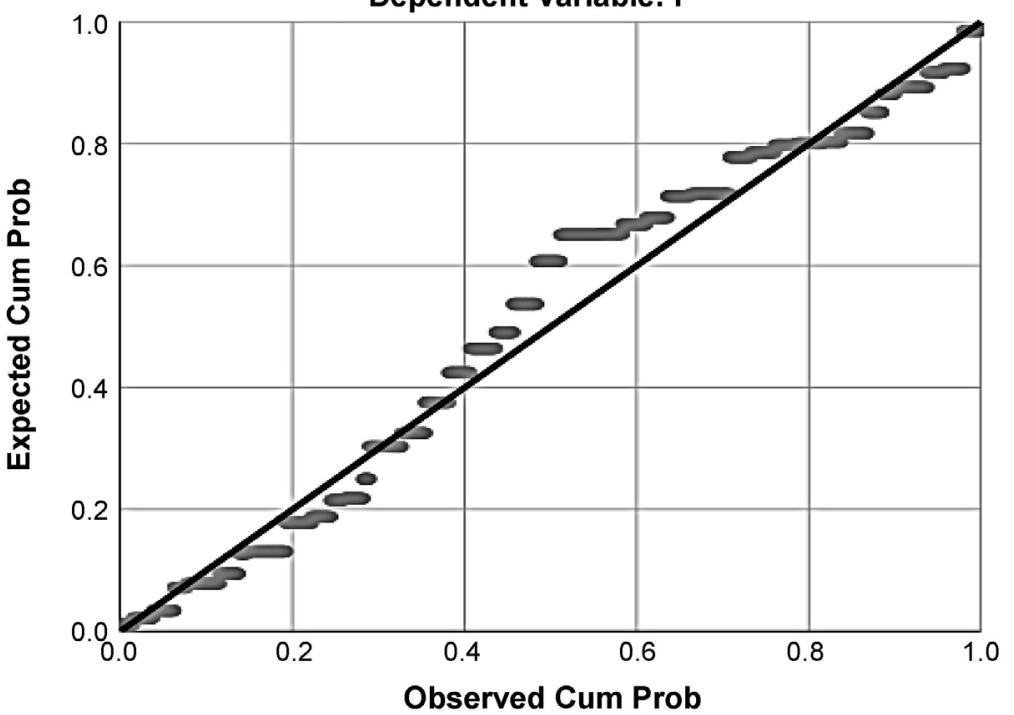

Figure 2. Normality plot of observed versus expected data.

variable up to the respective percentages realized by the model coefficients (Equation (3)). For instance, a 1 unit increase in the importance of considering journal citing preference (JCP) in the decision to choose a publisher (CP) will 


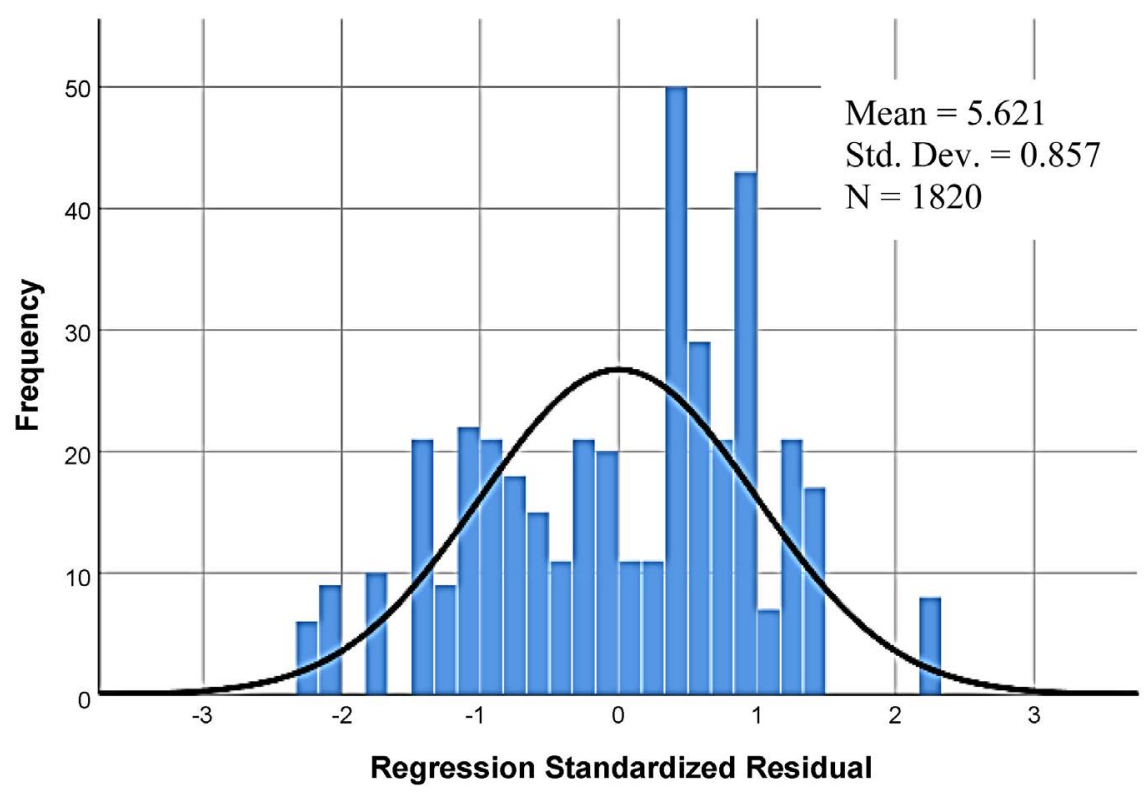

Figure 3. Histogram of distribution of data.

account for $49.1 \%$ variability in the final choice of publisher. Thus, $49.1 \%$ of the decision for a publisher is accounted for by the type of journal paper cited. In practical sense, the decision of a research student for a journal paper publisher is explained by the type of journal papers cited in the study up to about $50.0 \%, c e$ teris paribus. Considering model constants, JCP will influence CP by $7.41 \%$ $(6.917+0.491)$, without the effects of IF and HI computed. All the same, from regression equation (Equation (3)), IF $\left(r^{2}=0.667\right)$ was the best bibliometric measure that had the highest influence on $\mathrm{CP}$, followed by $\mathrm{HI}\left(\mathrm{r}^{2}=0.530\right)$ and JCP $\left(\mathrm{r}^{2}=0.491\right)$, and all effects were significant (Table 4).

\section{Assessment of hypothesis $\left(\mathrm{H}_{1}\right)$}

$\mathrm{H}_{1}$ : Journal citation preference (JCP) has a significant effect on researcher's choice of publisher (CP). Results have shown that JCP has a strong positive correlation (0.491) with CP (Table 4) according to regression model.

\subsection{Mediation Tests for IF and HI}

Results from mediation analysis with PROCESS macro assessment of direct and indirect effects, results confirmed a good relationship between JCP and CP as a direct or main relationship. The correlations of the level of direct and indirect effects are shown in (Figure 4) below. Considering the indirect effect of IF on the relationship between JCP and $\mathrm{CP}$, an $\mathrm{r}^{2}$ value of 0.588 with respective lower and upper confidence intervals (CI) of 0.114 and 0.271 was realized, against a direct effect of JCP on CP with $\mathrm{r}^{2}$ value of 0.434 without influence from IF or HI (Figure 4). This means, IF played a significant mediating role on the relationship between JCP and CP. Considering the mediating role of HI, an $\mathrm{r}^{2}$ value of 0.08 with lower and upper CIs of 0.086 and 0.133 respectively, a direct effect of JCP on CP $\left(\mathrm{r}^{2}=0.434\right)$ was higher and so, HI had no significant mediating role on the relationship between JCP and CP (Figure 4). 


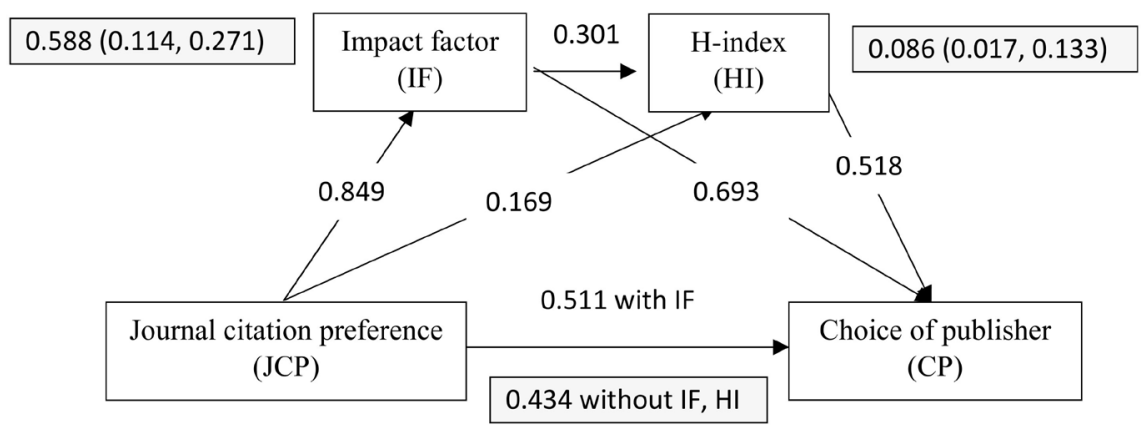

0.234 with $\mathrm{HI}$

Figure 4. Diagram depicting the relationship between variables and mediating effects of IF and HI.

Findings from this study can be explained by the fact that many researchers give IF a higher rating most often than other bibliometric indicators. According to [31], IF of a journal is often overused to evaluate the scientific competency and productivity of individual researchers and institutions. "Reference [32]" also leveled an investigation into the use of IF in evaluation journal performance and concluded that in the most probable scenario, IF evaluations fail up to about a probability of 0.50 . This over-concentration on IF puts less emphasis on the use of $\mathrm{HI}$ in evaluating the scientific competence of journals. This has been revealed in this study, in which results have shown a high mediation in favor of IF.

\section{Assessment of hypotheses $\left(\mathrm{H}_{2}\right.$ and $\left.\mathrm{H}_{3}\right)$}

$\mathrm{H}_{2}$ : Impact factor (IF) of journals plays a significant mediating role on the relationship between JCP and CP. The study has confirmed a strong mediating role of IF with an $r^{2}$ value of 0.588 as an indirect effect against a direct effect $r^{2}$ value of 0.434 .

$\mathrm{H}_{3}$ : $\mathrm{H}$-index (HI) plays a significant mediating role on the relationship between JCP and CP. Study results failed to confirm any significant mediating role played by $\mathrm{HI}$ per the stated hypothesis. $\mathrm{H}_{3}$ is therefore rejected.

\section{Conclusion}

The relationship between journal citation preference (JCP) of scholars and their choice for publisher (CP) for their research papers was evaluated as well as the mediating roles played by journal impact factor (IF) and H-index (HI) on this relationship. Study findings revealed that CP had a $49.1 \%, 66.7 \%$ and $53.0 \%$ chance of its variations being explained by a unit increase in JCP, IF and HI respectively. In practice, the decision of a research student for a journal paper publisher is explained by the type of journal papers cited in the study up to about $50.0 \%$, ceteris paribus. Owing to the bias observed in the over-usage of Impact factor (IF) in the evaluation of journal performance, it was found to have played a significant mediating role on the relationship between JCP and CP with an $\mathrm{r}^{2}$ of 0.588 against a 0.434 direct effect. On the contrary, HI had an $r^{2}$ of 0.086 against a direct effect coefficient of 0.434 and did not show significant media- 
tion. It implies therefore that $\mathrm{CP}$ is influenced mostly by IF of journals. More research is needed into understanding the role of IF and HI and under what circumstances they can be used appropriately without abuse and the creation of false hypes.

\section{Conflicts of Interest}

The authors declare no conflicts of interest regarding the publication of this paper.

\section{References}

[1] Porter, S.R. and Toutkoushian, R.K. (2006) Institutional Research Productivity and the Connection to Average Student Quality and Overall Reputation. Economics of Education Review, 25, 605-617. https://doi.org/10.1016/j.econedurev.2005.06.003

[2] Linton, J.D., Tierney, R. and Walsh, S.T. (2011) Publish or Perish: How Are Research and Reputation Related? Serials Review, 37, 244-257. https://doi.org/10.1016/j.serrev.2011.09.001

[3] Abrams, R.W., Abrams, J.F. and Abrams, A.L. (2018) Climate Change Challenges for Africa. Encyclopedia of the Anthropocene, 2, 177-194. https://doi.org/10.1016/B978-0-12-809665-9.09754-8

[4] Venn, A. (2019) 24-Social Justice and Climate Change. In: Letcher, T.M., Ed., Managing Global Warming. An Interface of Technology and Human Issues, Elsevier, Amsterdam, 711-728. https://doi.org/10.1016/B978-0-12-814104-5.00024-7

[5] Mouratiadou, I., Biewald, A., Pehl, M., Bonsch, M., Baumstark, L., Klein, D., Popp, A., Luderer, G. and Kriegler, E. (2016) The Impact of Climate Change Mitigation on Water Demand for Energy and Food: An Integrated Analysis Based on the Shared Socioeconomic Pathways. Environmental Science \& Policy, 64, 48-58. https://doi.org/10.1016/j.envsci.2016.06.007

[6] Hadjiyiannis, C., Heracleous, M.S. and Tabakis, C. (2016) Regionalism and Conflict: Peace Creation and Peace Diversion. Journal of International Economics, 102, 141-159. https://doi.org/10.1016/j.jinteco.2016.07.001

[7] Gödecke, T., Stein, A.J. and Qaim, M. (2018) The Global Burden of Chronic and Hidden Hunger: Trends and Determinants. Global Food Security, 17, 21-29. https://doi.org/10.1016/j.gfs.2018.03.004

[8] Ngo, J. and Serra-Majem, L. (2019) Hunger and Malnutrition. Encyclopedia of Food Security and Sustainability, 2, 315-335. https://doi.org/10.1016/B978-0-08-100596-5.22064-7

[9] Heyeres, M., Tsey, K., Yang, Y., Yan, L. and Jiang, H. (2019) The Characteristics and Reporting Quality of Research Impact Case Studies: A Systematic Review. Evaluation and Program Planning, 73, 10-23. https://doi.org/10.1016/j.evalprogplan.2018.11.002

[10] Hu, C.-S. (2019) Scientific Papers: Which Type Would You Prefer? Journal of Integrative Medicine, 17, 77-79. https://doi.org/10.1016/j.joim.2019.02.003

[11] Kovacs, G. and Moshtari, M. (2019) A Roadmap for Higher Research Quality in Humanitarian Operations: A Methodological Perspective. European Journal of $O p$ erational Research, 276, 395-408. https://doi.org/10.1016/j.ejor.2018.07.052

[12] Baney, A. (2008) "Publish or Perish" as Citation Metrics Used to Analyze Scientific Output in the Humanities: International Case Studies in Economics, Geography, 
Social Sciences, Philosophy, and History. Archivum Immunologiae et Therapiae Experimentalis, 56, 363-371. https://doi.org/10.1007/s00005-008-0043-0

[13] Barner, J.R., Holosko, M.J., Thyer, B.A. and King, S. (2015) Research Productivity in Top-Ranked Schools in Psychology and Social Work: Does Having a Research Culture Matter? Journal of Social Work Education, 51, 5-18. https://doi.org/10.1080/10437797.2015.977123

[14] Blagus, R., Leskosek, B.L. and Stare, J. (2015) Comparison of Bibliometric Measures for Assessing Relative Importance of Researchers. Scientometrics, 105, 1743-1762. https://doi.org/10.1007/s11192-015-1622-6

[15] Cheng, K.L., Dodson, T.B., Egbert, M.A. and Susarla, S.M. (2017) Which Factors Affect Citation Rates in the Oral and Maxillofacial Surgery Literature? Journal of Oral and Maxillofacial Surgery, 75, 1313-1318.

https://doi.org/10.1016/j.joms.2017.03.043

[16] Davalos, S. (2015) One Way to Evaluate the Impact of Scientific Research. Madera $y$ Bosques, 21, 7-16.

[17] Hodge, D.R., Victor, B.G., Grogan-Kaylor, A. and Perron, B.E. (2017) Disseminating High-Impact Social Work Scholarship: A Longitudinal Examination of 5-Year Citation Count Correlates. Journal of the Society for Social Work and Research, 8, 211-231. https://doi.org/10.1086/691463

[18] Tijdink, J.K., Schipper, K., Bouter, L.M., Pont, P.M., de Jonge, J. and Smulders, Y.M. (2016) How Do Scientists Perceive the Current Publication Culture? A Qualitative Focus Group Interview Study among Dutch Biomedical Researchers. BMJ Open, 6, e008681. https://doi.org/10.1136/bmjopen-2015-008681

[19] Lacasse, J.R., Hodge, D.R. and Bean, K.F. (2011) Evaluating the Productivity of Social Work Scholars Using the h-Index. Research on Social Work Practice, 21, 599-607. https://doi.org/10.1177/1049731511405069

[20] Mingers, J. and Yang, L.Y. (2017) Evaluating Journal Quality: A Review of Journal Citation Indicators, and Ranking in Business and Management. European Journal of Operational Research, 257, 323-337. https://doi.org/10.1016/j.ejor.2016.07.058

[21] Qian, Y.F., Rong, W.G., Jiang, N., Tang, J. and Xiong, Z. (2017) Citation Regression Analysis of Computer Science Publications in Different Ranking Categories and Subfields. Scientometrics, 110, 1351-1374.

https://doi.org/10.1007/s11192-016-2235-4

[22] Lopez, J., Susarla, S.M., Swanson, E.W., Luck, J.D., Tuffaha, S. and Lifchez, S.D. (2016) The Effect of Self-Citations on the Hirsch Index among Full-Time Academic Hand Surgeons. Journal of Surgical Education, 73, 317-322. https://doi.org/10.1016/j.jsurg.2015.10.012

[23] Susarla, S.M., Swanson, E.W., Lopez, J., Peacock, Z.S. and Dodson, T.B. (2015) Does Self-Citation Influence Quantitative Measures of Research Productivity among Academic Oral and Maxillofacial Surgeons? Journal of Oral and Maxillofacial Surgery, 73, 1981.e1-1981.e7. https://doi.org/10.1016/j.joms.2015.05.018

[24] Swanson, E.W., Miller, D.T., Susarla, S.M., Lopez, J., Lough, D.M., May, J.W. and Redett, R.J. (2016) What Effect Does Self-Citation Have on Bibliometric Measures in Academic Plastic Surgery? Annals of Plastic Surgery, 77, 350-353. https://doi.org/10.1097/SAP.0000000000000585

[25] Tanner-Smith, E.E. and Polanin, J.R. (2016) Brief Alcohol Intervention Trials Conducted by Higher Prestige Authors and Published in Higher Impact Factor Journals Are Cited More Frequently. Journal of Clinical Epidemiology, 75, 119-125. https://doi.org/10.1016/j.jclinepi.2016.01.028 
[26] Diem, A. and Wolter, S.C. (2013) The Use of Bibliometrics to Measure Research Performance in Education Sciences. Research in Higher Education, 54, 86-114. https://doi.org/10.1007/s11162-012-9264-5

[27] Harzing, A.W. and van der Wal, R. (2009) A Google Scholar h-Index for Journals: An Alternative Metric to Measure Journal Impact in Economics and Business. Journal of the American Society for Information Science and Technology, 60, 41-46. https://doi.org/10.1002/asi.20953

[28] Hirsch, J.E. (2005) An Index to Quantify an Individual's Scientific Research Output. Proceedings of the National Academy of Sciences of the United States of America, 102, 16569-16572. https://doi.org/10.1073/pnas.0507655102

[29] Jasco, P. (2008) The Pros and Cons of Computing the h-Index Using Google Scholar. Online Information Review, 32, 437-452. https://doi.org/10.1108/14684520810889718

[30] Hodge, D.R. and Lacasse, J.R. (2011) Evaluating Journal Quality: Is the H-Index a Better Measure Than Impact Factors? Research on Social Work Practice, 21, 222-230. https://doi.org/10.1177/1049731510369141

[31] Link, J.M. (2015) Publish or Perish...But Where? What Is the Value of Impact Factors? Nuclear Medicine and Biology, 42, 426-427. https://doi.org/10.1016/j.nucmedbio.2015.01.004

[32] Brito, R. and Rodríguez-Navarro, A. (2019) Evaluating Research and Researchers by the Journal Impact Factor: Is It Better than Coin Flipping? Journal of Informetrics, 13, 314-324. https://doi.org/10.1016/j.joi.2019.01.009 